\title{
Brain drain and the Second Wave of Depopulation
}

Miguel González-Leonardo, Antonio López-Gay and Joaquín Recaño, Centre for Demographic Studies and Department of Geography, Autonomous University of Barcelona

The territorial imbalances among the autonomous Spanish communities result in emigration of university-educated people in some regions and concentrations of qualified human capital in others. The hinterland of the peninsula and the Cantabrian coast, where the intensity of outflows became more serious with the turn of the century, are affected by the dynamics of educational decapitalisation and emigration of young people of their cities. Depopulation is no longer a phenomenon that is exclusive to rural areas. It has extended to the urban milieus of the traditional sending autonomous communities. Castile and León is the most affected region, with annual migration losses due to long-distance mobility -interregional and abroad- of $-13.4 \%$ o among the young people of the capitals of the province, $-9.25 \%$ o in other urban municipalities, and $-9.63 \%$ in rural areas. To this migration deficit must be added the high levels of qualifications of the emigrants, since more than $53.8 \%$ of young people who leave have university studies and only $36.7 \%$ of who arriving from elsewhere in Spain are equally qualified. Madrid is the main receiver of talent, bringing together $38.7 \%$ of the interregional migratory movements of young Spanish people whose inflows present high levels of education. In this group, $64.8 \%$ are university degree holders. In this issue of Perspectives Demogràfiques we analyse the migratory movements of Spanish-born population between 25and 39 years who crossed some autonomous region border from 2013 to 2017, focusing on interregional flows, the educational level of these exchanges, and the migratory balance according to the territorial setting (urban and rural). In order to do so, we analyse the data from Statistics on Residential Variations (EVR) and the Active Population Surveu (EPA).

\section{MADRID: MAIN DESTINATION OF SPAIN'S INTERNAL MIGRATION}

Most long-distance migratory flows come from peripheral areas, heading for others that act as centres of the territorial system in which global cities are located (Sassen, 1991). According to EVR data, between 2013 and 2017, 776,345 Spanishborn people aged between 25 and 39 undertook long-distance migration, with an annual flow of 155.269 such movements, $80.7 \%$ of them within national limits, and $19.3 \%$ with an origin or destination abroad. Figure 1 shows, in a circular graph, the direction and bulk of migratory flows between Spain's autonomous communities. Of these interregional movements, $38.7 \%$, or 48,505 people, arrived in or left the Community of Madrid, with 29,320 people coming in per year and 19,185 leaving, with a positive net flow of 10,135 young people, which is the highest figure for the country as a whole. Some ten thousand of these immigrants, or 35\%, come from Castile-La Mancha and Castile and León. Part of the losses in the former region is compensated by the decentralisation of Madrid towards the northern sector of the La Mancha region. This is not the case of Castile and León where there is
FIGURE 1. Interregional migratory flows for the Spanish-born population aged between 25 and 39 years: average annual flow for the period 2013-2017

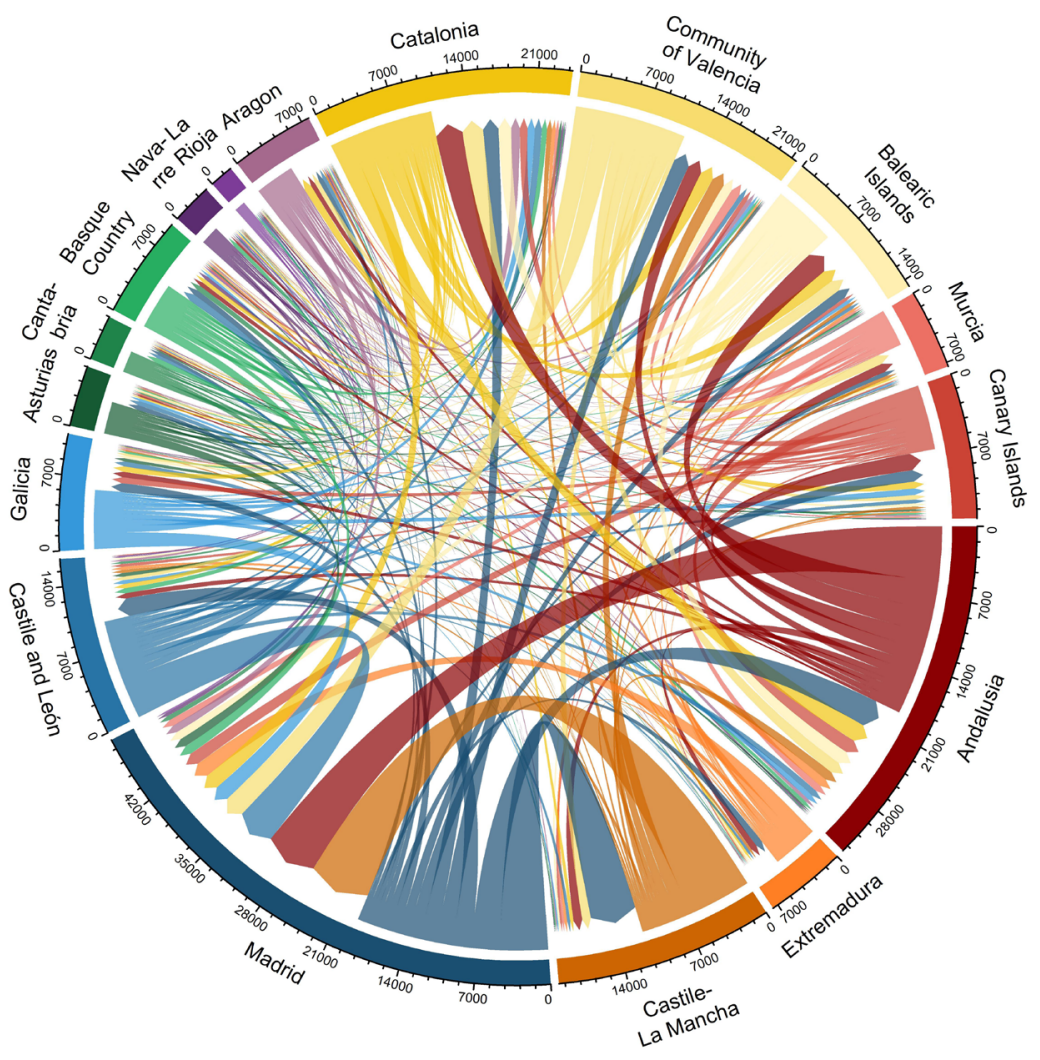

Source: Compiled by authors using Residential Variation Statistics (INE). 
very slight inflow from the Spanish capital. Extremadura, Galicia, Asturias, Cantabria, Andalusia, the Community of Valencia, the Canary Islands, and Catalonia also have notable migrant quotas heading for Madrid but without major losses in the last three cases.

Far from having Madrid's pull power, Catalonia is the second reception centre with 10,443 emigrants and 13,654 immigrants per year, or a positive balance of 3,211 young people who mainly come from Andalusia, the Community of Valencia and, to a lesser extent, the Balearic Islands, Madrid and Aragon. Catalonia registers a certain surplus with respect to Andalusia and the Community of Valencia, but the balance between emigrants and immigrants remains stable with the other three autonomous communities. The Balearic Islands also have a significant net balance and are mainly fed by populations from Mediterranean regions with a marked migratory rotation deriving from the seasonal nature of tourism. The other interregional flows are not very significant in quantitative terms, and outflows are more or less compensated by inflows from other parts of Spain.

\section{BRAIN DRAIN AND ACCUMULATION OF QUALIFIED HUMAN CAPITAL}

Brain drain refers to the loss of qualified human capital in a territory (Docquier y Rapoport, 2012). The emigration of local talent has negative consequences for endogenous development and fuels processes of accumulation in the receiving areas, which benefit from the imported human capital (González-Leonardo and López-Gay, 2019). Mobility is explained by the rational action of individuals seeking to obtain higher yields for their abilities, which are better rewarded in places occupying the upper levels in the territorial hierarchy (Sánchez-Moral et al., 2018). The greater the mismatch between skills and the returns paid for these in the regions of origin, the more significant the impact of the brain drain. Non-economic factors such as the offer of cultural activities and diversity should also be taken into account when considering the choice of one's place of residence (Florida, 2002), although the economic variables -employment, salary, and personal networkshave greater influence in the decision to move (Martin-Brelot et al., 2010). In general, migrants tend to be positively selected with regard to the population of origin (Bernard y Bell, 2018). Nevertheless, selectivity can also be negative in some contexts, especially when push factors are more significant.

According to EPA data for the period 2013-2017 (Figure 2), there is positive migration selectivity in the interregional movements of young Spanish people, measured on the basis of the population with university studies, in all the communities except in Catalonia and Madrid. In other words, Spanish-born people aged between 25 and 39 who have emigrated have a higher level of education with regard to their counterparts who remain in the regions of their birth. Castile and León, Galicia, Asturias, Navarre, CastileLa Mancha, Cantabria, and Valencia are the communities with the most marked emigration selectivity. Between $45 \%$ and $55 \%$ of the young people who leave have a university education by comparison with $30 \%$ to $35 \%$ of those who remain. In Madrid, however, $42.9 \%$ of the autochthonous residents had university degrees and, in the case of the emigrants, the figure was $30.1 \%$. Hence, there is a notable character of negative selectivity in the outgoing flows and a tendency towards sociodemographic selection of the population resident in Madrid.

FIGURE 2. Percentage of the Spanish-born population of between 25 and 39 years of age with university degrees, by autonomous community and migratory status: 2013-2017

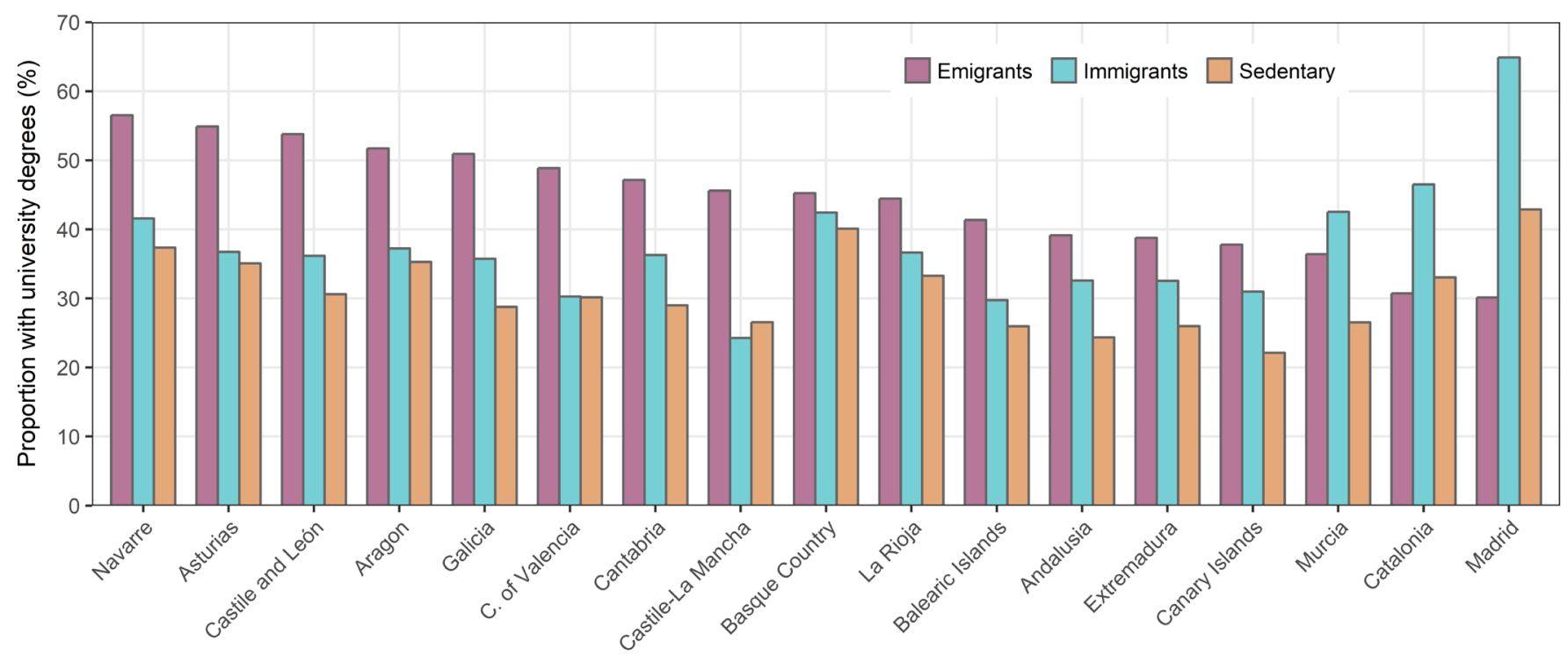

Source: Compiled by authors using Economically Active Population (INE). 
If the educational profile of the emigrating population is compared with that of people arriving from other autonomous communities, one sees that the former group is much more highly qualified than the latter in the same regions where migration selectivity is more marked. Consequently, this means that not only that more qualified people are leaving but also that young people coming in from other regions have a lower educational level than those who leave. In Castile and León, only 36.7\% of people born in other autonomous communities and residing in the region have a university degree compared with $53.8 \%$ of local people who have emigrated to other parts of Spain. In Castile-La Mancha, the percentages are 45.6 and 24.3, in that order. Only in Madrid and Catalonia, in addition to Murcia, do the immigrants have higher levels of education than emigrants. In the Community of Madrid, $64.9 \%$ of young people coming from other regions have university studies by comparison with $30.1 \%$ among the emigrant group. Madrid is therefore positioned as the leading importer of talent coming from other parts of Spain while it also expels young people without university studies to places where it is cheaper to live. A large part of this latter group moves to the provinces of Guadalajara and Toledo while still working in Madrid and commuting.

\section{PROVINCIAL CAPITALS OF THE OUTFLOW REGIONS ARE DEPOPULATING}

Depopulation is the result of demographic processes that go a long way back. Since the second half of the nineteenth century, emigration of the rural population to cities kept increasing and it became acute between the end of the 1950s and the mid-1970s when there was a massive rural exodus (Recaño, 2017). From then on, the intensity of emigration has lessened, although the rural population is still constantly trickling out. Meanwhile, rural-urban migration is now less important because the rural areas have a lower capacity for sending young people to cities. The polarisation of cities also increases as a consequence of the processes of globalisation. As a result, the significance of interurban migratory flows towards the first-level metropolitan areas of the territorial hierarchy has increased (Sánchez-Moral et al., 2018; González-Leonardo and López-Gay, 2019).

According to EVR data for the years studied (Figure 3), the provincial capitals of the outflow regions are the municipalities that lose the most young people aged between 25 and 39 to long-distance migration, with figures higher than those for other urban and rural areas. Once again, Castile and León is the hardest hit autonomous community with a negative annual rate of $-13.4 \%$ in the provincial capitals, $-9.25 \%$ in the conglomerate of the remaining urban municipalities, and $-9.63 \%$ in the rural areas. The same thing happens in CastileLa Mancha and Asturias, and also in Cantabria, Andalusia, and Galicia, although in these latter cases, the net negative rates are not so intense. The provincial capitals of these autonomous communities not only lose population born in a municipality but they are also used as a springboard for young people from smaller towns and rural areas of the same region who initially move to their provincial capitals to study or join the job market, after which they emigrate to larger urban areas. The other side of the same coin is to be found in the municipality of Madrid with an average annual migratory growth of $16 \%$.

FIGURE 3. Net annual rates of migration for the Spanish-born population of between 25 and 39 years of age, by autonomous community and territorial area: 2013-2017

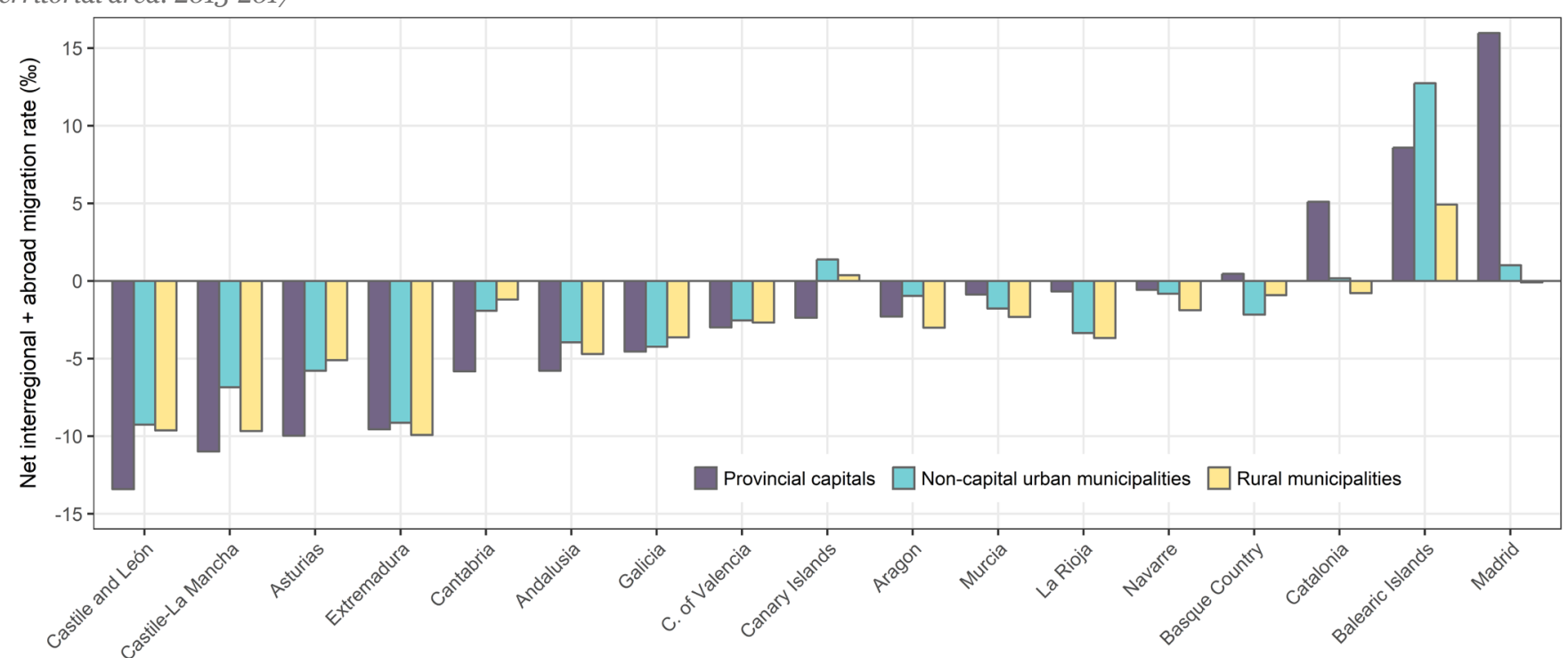

Source: Compiled by authors using Residential Variation Statistics and the Municipal Register of Inhabitants (INE).

Note: Urban municipalities are considered to be those with more than 10,0oo inhabitants and others of a smaller size included in the Statistical Atlas of Urban Areas of the Ministry of Public Works and Transport. 
The population increase in the remaining urban municipalities of the Community of Madrid is contained, while the balance for the rural environment is close to zero. The Balearic Islands show positive net rates, highlighted in the three territorial typologies, especially in towns and cities that are not capitals. The spatial distribution of tourist activity in the Balearic Islands has considerable bearing on this question. The Catalan capitals are also growing with the arrival of young people from Spain, mainly at the expense of inflows to Barcelona.

\section{EMIGRATION, EDUCATIONAL DECAPITALI-} SATION, AND URBAN DEPOPULATION: AN INCREASINGLY POLARISED TERRITORY

The traditional sending autonomous communities not only show negative migration balances for the young population, but also their outflows are characterised by quite an intense exodus of university graduates, while the inflows have lower educational levels. The urban municipalities of these regions, mainly the provincial capitals, have serious difficulty in keeping young people in the territory, especially the better educated among them. This latter group tends to emigrate to places at the top of the territorial hierarchy because of a lack of employment opportunities in keeping with their educational level. Hinterland regions and those in the north of Spain are the worst affected, especially Castile and León where the negative migration balance of their capitals and the outflow of university degree holders are particularly noteworthy. These cities, small and intermediate towns of the Spanish urban fabric, present scant competiveness in today's globalised economy.

\section{Bibliography}

Bernard, A.; Bell, M. (2018). "Educational selectivity of internal migrants". Demographic Research, 39 (29): 835-854

Docquier, F.; Rapoport, H. (2012). "Globalization, Brain Drain, and Development". Journal of Economic Literature, 50 (3): 681-730.

Florida, R. (2002). "The Economic Geography of Talent". Annals of the Association of American Geographers, 92 (4): $743-755$

González-Leonardo, M.; López-Gay, A (2019). "El nuevo paradigma de las migraciones internas en España: migrantes urbanos más móviles y cualificados. El caso de Castilla y León”. Scripta Nova. Revista Electrónica de Geografía y Ciencias Sociales, 23 (609): 1-37.

Martin-Brelot, H.; Grossetti, M.; Eckert, D.; Gritsai, O; Kovácz, Z. (2010). "The Spatial Mobility of the Creative Class: A European Perspective". International Journal of Urban and Regional Research, 34 (4): 854-870.

They have been excluded from big capital investments, both national and international, and have not been able to create an economy based on the new technologies taking advantage of local human capital. In many cases these are towns and cities that have not recovered from the processes of deindustrialisation, or that are still trying to sustain a production system showing a certain degree of obsolescence and a major deficit of activities with high added value.

Madrid is consolidated as the chief agglomeration of talent coming from other parts of Spain with notable processes of accumulation of qualified human capital and dynamics of expulsion that affect people of lower social and educational strata whose flows mostly go to the provinces of Guadalajara and Toledo. Barcelona is also positioned as a net gainer of qualified human capital from elsewhere in Spain, although it is a long way from having the centripetal force of the Spanish capital. The Balearic Islands show a positive migration balance, but the educational profile of the immigrants is lower as the tourist sector in the islands has a high demand for low-skilled workers. The results draw attention to a marked and increasing polarisation of the Spanish territory with serious processes of educational decapitalisation in the outflow regions where depopulation is no longer a process exclusive to the rural environment but one that extends to urban milieus. Meanwhile, there are dynamics of accumulation, mainly in Madrid, which testify to the inherent tendency of the processes of globalisation to concentrate capital, activities of high added value, and highly educated population in just a few global cities.

Please address correspondence to:

Miguel González-Leonardo

mgonzalez@ced.uab.es

Credits

Graphics: Anna Turu

Layout: Xavier Ruiz Vilchez

\section{Acknowledgements:}

Our thanks to the editors for inviting us to participate in this publication and for their comments during the process of writing. We also thank Pau Miret and Teresa Menacho for their help with methodological questions related with the Active Population Survey, and Anna Turu for her involvement in producing the graphs.

This work has been funded by means of an FI Grant as part of the project "Integrating Research Infrastructure for European expertise on Inclusive Growth from data to policy -InGRID2-" (730998). Economic support has also been given by the project “Comportamientos demográficos y estrategias residenciales: apuntes para el desarrollo de nuevas políticas sociales" [Demographic behaviour and residential strategies: notes for the development of new social policies] (CSO2016-79142-R).

URL

http://ced.uab.es/en/difusion/butlletiperspectives-demografiques

Contact

Centre d'Estudis Demogràfics. Carrer de Ca n'Altayó, Edifici E2 Universitat Autònoma de Barcelona o8193 Bellaterra / Barcelona Spain

Telephone: +34935813060 Email:demog@ced.uab.cat Web page: www.ced.uab.cat
Andreu Domingo and Albert Esteve (Centre for Demographic Studies) 